\title{
Application of artificial intelligence in the field of geotechnics and engineering education
}

\author{
Victoria Lez'er ${ }^{1}$, Nina Semeryanova ${ }^{2}$, Anna Kopytova ${ }^{I^{*}}$, Irina $\mathrm{Kvach}^{3}$ \\ ${ }^{1}$ Tyumen Industrial University, Volodarskogo str., 38, Tyumen, 625000, Russia \\ ${ }^{2}$ South Ural State University (National Research University), Nizhnevartovsk Branch, Mira str., 9 , \\ 628600, Russia \\ ${ }^{3}$ Ugra State University, Chekhov str., 16, Khanty-Mansiysk, 628012, Russia
}

\begin{abstract}
The work is devoted to the theoretical and legal study of the features of the application of artificial intelligence in geotechnics and engineering education. The conceptual approaches to the definition of the concept of artificial intelligence, the problems of its use, and the features of legal regulation are considered. In this paper, for the first time, artificial intelligence in the geological industry was studied through the prism of engineering education, a logical correlation of the provisions on artificial intelligence in the field of engineering education, the practice of using artificial intelligence in geotechnics was traced. It is concluded that a strategically important task can be realized only through the formation of an institutional environment based on the principles of partnership of educational institutions and engineering business for the development of innovative research and educational programs focused on employer requests to increase the level of specialized education in the application of artificial intelligence in the field of geotechnics.
\end{abstract}

\section{Introduction}

The relevance of the study is due to the issues of the legal regulation of technologies for the creation and implementation of artificial intelligence in almost all areas of our activity, including education, science, medicine, business, entertainment, the fight against crime, and others. Attitude towards artificial intelligence that is rapidly filling our reality is unequivocal. Some scientists are skeptical about the issue of artificial intelligence, because they believe that there are many problems that have not yet been solved by scientific means. Others believe that, over time, artificial intelligence will take a worthy place next to a person, reproducing his thought processes, which will facilitate our work or take on some of our responsibilities (I.V. Ponkin, A.I. Redkina). However, we see that artificial intelligence is successfully being improved and is actively being introduced into practical activity, including in the field of geotechnics. The wide dissemination of artificial intelligence is due to the automation of production, processing and analysis of a huge amount of information and making quick, just right decision. In this capacity, artificial intelligence produces better results than humans.

*Corresponding author: a.copytowa@,yandex.ru 
The story began in 1956, year of creation of artificial intelligence. Artificial intelligence is a fairly young area of scientific research that has had different popularity in different decades. As already noted, the topic of artificial intelligence is nowadays at the peak of world popularity. Research in this area is growing every year, and along with it, the number of issues that need to be resolved increases, for example, where such studies lead, where the limits of artificial intelligence lie, in which areas of science and practice we interfere, what is the peculiarity of artificial ability of rational thinking or intellectual action, is there a threat to humanity? British scientist Stephen Hawking warned mankind about the development of artificial intelligence as the real reason for the possible destruction of the human race. In April 2017, during a video conference in Beijing, held at the Global Mobile Internet Conference, he stressed that the development of artificial intelligence can be both the most positive and the most terrible factor for mankind. We must be aware of the danger he presents. [1] People, he believes, can create too powerful artificial intelligence that will be extremely good at achieving their goals. And if these goals do not coincide with human goals, then people will have problems. [2]

The issue of artificial intelligence is truly unique in terms of the breadth and diversity of scientific knowledge and engineering techniques, psychological models and philosophical ideas involved in solving it. Without dwelling on ethical standards and safety issues of using artificial intelligence, let us turn to the problem of its use in geotechnics, as well as the need to train students of building and engineering specialties in artificial intelligence programs for the future application of their knowledge in the geotechnical space.

Certainly, robotics and artificial intelligence have become one of the most famous and actively discussed technological trends of our century. [3]

Any new attitude should be settled in order to ensure the smooth movement of subjects' interests in values, i.e. to guarantee their fair satisfaction, removal of possible obstacles that stand in the way of the interests of the subjects. Act of August 31, 2017 of the European Economic and Social Committee "Artificial Intelligence - the consequences of artificial intelligence in the (digital) single market, in production, consumption, employment and society"[4] artificial intelligence is presented as a method that contributes to the achievement of many goals, in particular, the goals of eradicating poverty, ensuring safety of transport, quality medicine, more personalized education, and developing industry. The Royal Academy of Engineering of Great Britain believes that artificial intelligence can be used to solve a variety of economic and social problems, including in situations and places where human presence can be dangerous, as part of a response to natural disasters and manmade disasters; for the use of underground probes when conducting geodetic exploration work in the development of oil and gas, in the field of security, etc. [5]

In Russia, the provisions on artificial intelligence are enshrined in the Program "Digital Economy of the Russian Federation", approved by the decree of the Government of the Russian Federation No. 1632-p1 of July 28, 2017 [6], by decree of the Government of the Russian Federation No. 482-p dated March 23, 2018 (as amended on 10.20.2018) "On approving an action plan ("road map") to improve legislation and eliminate administrative barriers in order to ensure the implementation of the National Technology Initiative in the Technet direction (advanced production technologies)" [7], Strategies for the development of the information technology industry in the Russian Federation for 2014-2020. and for the future up to 2025. [8]

The goal of this study is to address the question of how to use artificial intelligence in geotechnics and engineering education. Problems of legal regulation of artificial intelligence are numerous. The main issues include determining the status of artificial intelligence as a subject or object of relations. Thus, technologies that use artificial intelligence are regulated as objects of copyright or as property. A common suggestion is to apply the norms on legal entities to such systems. [9] Since a legal entity is an artificially 
constructed subject of law, [10] robots endowed with artificial intelligence can also be given a similar status. [11] However, difficulties in using artificial intelligence are caused not only by problems of legal regulation. The use of artificial intelligence in the oil and gas industry, artificial neural networks, and the main areas of its application technologies - the interpretation of geological data, the exploitation of fields (smart fields) and price forecasting are considered by P. Kaznacheev, R. Samoylova, N. Kruchinski. In their opinion, using methods based on artificial intelligence increases the efficiency of the work carried out, both in exploration and mining, makes it possible to achieve better results with less costs. In this regard, the process of teaching students of future engineering specialties, whose knowledge should be based on the methods of using artificial intelligence in the educational sphere, is definitely important.

The ambiguous attitude of the scientific community to the development and use of artificial intelligence in geotechnics entails issues of the basic and human sciences.

1) The first issue can be described as relating to the phenomenon of "artificial intelligence"

2) Problems in the use of artificial intelligence in geotechnics

The need to use artificial intelligence in obtaining engineering education.

\section{Methods}

Logical approach Let us turn to etymology and logically define the definition of "artificial intelligence." An outstanding American computer scientist, the author of the term "artificial intelligence" defines it as follows: "Artificial Intelligence (AI)" is the science and technology of creating intelligent machines, especially intelligent computer programs. Artificial intelligence is associated with a similar task of using computers to understand human intelligence, but is not necessarily limited to biologically plausible methods. [12] At the same time, there is a point of view saying that intelligence can only be a biological phenomenon. [13]

Thus, "artificial intelligence" can be defined as the field of computer science that develops intelligent computer systems, systems that have the capabilities of the human mind, language understanding, learning, imagination, perception, memory, the ability to reason, solve problems, etc. In fact, artificial intelligence is able to model human activity, which is considered intellectual. A vivid well-known example is the game of chess, when artificial intelligence learns by analyzing a person's game, and each time makes it better and better. If the program simply acquires values from the base according to certain rules, it is not endowed with artificial intelligence. If after training the system creates programs, methods and documents, solving certain tasks, it possesses artificial intelligence.

In connection with the issue of research, this definition should be considered logically in connection with the questions of the doctrinal definition of certain conceptual categories, such as "geotechnics" and "engineering geology". This problem was raised by a number of scientists (M.S. Zakharov), who noted that the concept of geotechnics is in fact synonymous with the concept of engineering geology abroad; in Russia (in the Soviet and post-Soviet period) for a long time it was possible to distinguish between these forms scientific and practical activities, although the task of their interaction in the construction process has always been relevant. The field of geotechnics has always included the issues of foundation engineering and all the tasks of design and construction, and engineering geology was dealing with the whole range of questionss of geological support for the preparation of project documentation and maintenance of the construction and operation of various buildings and structures. [14]

2. This implies the axioms that any human engineering activity must be based on knowledge of the laws governing the development of geological processes and phenomena. The catastrophic consequences of neglect of this situation are observed throughout the 
planet. This is especially true for objects of increased danger, first of all, such as objects of use of atomic energy, high-rise construction, underground construction, etc. At the same time, geodynamic regularities are always stochastic in nature. Risk assessment and forecast of changes in geotechnical conditions over time are impossible without attracting not only the current, but historical time scale, which is characteristic of the scientific method of all the earth sciences, including engineering geology. [14]

3. Methods of application of AI in engineering education.

Currently, experts are actively searching for the best ways to effectively use artificial intelligence in the process of teaching students. There were held researches in the field of existing methods of knowledge structuring and their application in the development of intelligent learning systems based on the structure of human knowledge, principles of development of artificial intelligence systems and information semantic systems, combining procedural and declarative approaches to the representation of knowledge based on the theory of semantic networks and production rules (T.Sh. Shikhnabiyeva). The use of individual methods of artificial intelligence in computer-aided training, such as computer training instructions (Tutor), computer programs of exercises (Trainer / Coach), computer modeling were studied (V.I. Bozhich, N.V. Gorbatyuk, A.V. Nepomnyashchy, J.M. Gibner, V.M. Malyutin, E.A. Sklyarova, T.V. Pen), the capabilities of the training systems Scholar, Guidon, LISP-Tutor were studied (O.N. Evseyeva). Research was held in the field of the combined model of information processes that can be used to create an intelligent learning system (A.A. Bolshakov, A.Yu. Markelov). The issues of creating artificial intelligence in the field of the ethical, social and philosophical aspects were studied (V.S. Doroganov, M.I. Bouamgarten).

4. Methods of legal regulation of artificial intelligence are seen as necessary, since the problem of the regulator lagging behind modern technological development, which is intensively generating new challenges, is extremely difficult to comprehend risks and polyvariance. The methods of legal regulation of AI were considered by I.V. Ponkin, A.I. Redikin.

\section{Results}

In September 2015, Integra Gold announced the start of the Gold Rush Challenge contest with a prize fund of $\$ 1$ million. The participants got access to almost $26 \mathrm{~GB}$ of initial geological data. They had to analyze the data and find a new large field in the area of the Sigma and Lamaque mines (Val-d'Or, Quebec, Canada). The first place was taken by the Quebec company SGS Geostat. SGS Geostat's approach to machine learning was based on data analysis. The SGS Geostat specialists interpolated and extrapolated historical data, making a block model on their basis, and then used the software of their own development, Genesis, which managed to be connected with the virtual reality device Oculus Rift. This made it possible to plan the scheme of boreholes and calculate the angle and orientation of suitable objects for the study. The SGS Geostat team operated with two assessment systems - a geological knowledge-based ranking system and objective baseline data, where gold mineralization is located. Thus, the use of artificial intelligence has led to a quick positive result. The company plans to develop and integrate this approach to software. In the future, they believe, such software will be in great demand, since modern methods (such as hyperspectral core scanning) provide extremely rich data. Of course, the further application of artificial intelligence in the field of geotechnics is a promising direction. However, the use of such software, building computer modeling as a teacher for students of construction and engineering areas in order to acquire skills and abilities when working with these programs, seems to be extremely necessary. 
According to the results of the study, development index of artificial intelligence and dynamics of its integration into society (telegram channel SmartPlanet) presented the following indicators: the number of students enrolling in an artificial intelligence course at Stanford University since 1996 and at the end of 2017 was $+1100 \%$, scientific works on artificial intelligence from 1996 to the end of 2017 accounted for $+900 \%$, American startups developing artificial intelligence systems from 2000 to 2017 accounted for $+1,400 \%$; the share of jobs in the United States requiring skills in working with artificial intelligence from 2000-2017 accounted for $+450 \%$; volume of venture capital investments in American startups, developing artificial intelligence systems from 2000-2017 accounted for $+600 \%$.

According to Rostec, the world market for artificial intelligence will grow annually and will increase to $\$ 59.75$ billion by 2025 (Table 1)

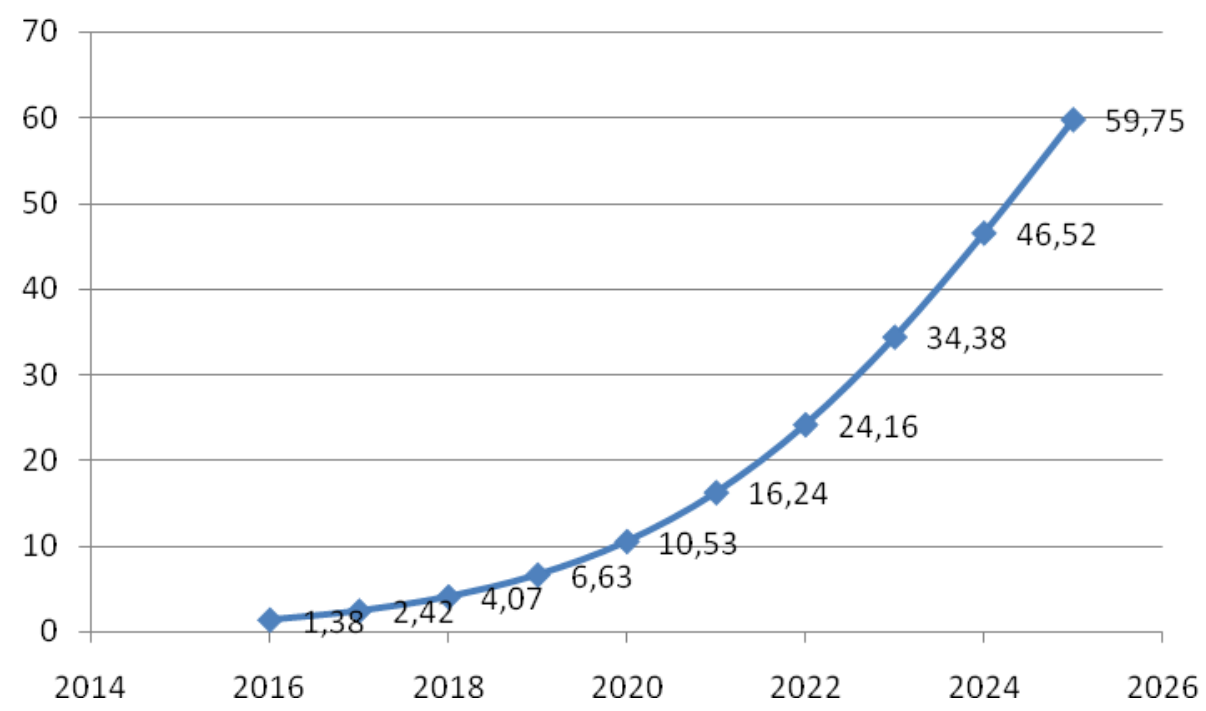

Fig. 1. The volume of the world market of artificial intelligence, billions of dollars

During the practical conference "Machine Learning Technologies" held by the Open Systems publishing house (Artificial Intelligence entered the business, Computerworld Russia, October 12, 2018), OSP Data analytic agency conducted a survey of participants. The results are in table 1.

Table 1. The scope of artificial intelligence systems, $\%$

\begin{tabular}{|c|c|c|}
\hline № & Direction & $\begin{array}{c}\text { Answers of respondents } \\
\text { (it was possible to choose } \\
\text { several answers) }\end{array}$ \\
\hline 1 & Predictive analytics & 67 \\
\hline 2 & Real-Time Process Management & 42 \\
\hline 3 & Work with clients, studying their \\
preferences & 42 \\
\hline 4 & Risk management and anti-fraud & 25 \\
\hline 5 & Other & 25 \\
\hline
\end{tabular}


According to the results of the survey, the area of application of artificial intelligence in predictive analytics is $67 \%$, which directly confirms the positive trajectory of using geotechnical forecast using artificial intelligence in the oil and gas industry and exploration spheres of the Russian economy.

In this regard, the use of artificial intelligence in carrying out exploratory activities in engineering geology will contribute to carrying out these works more effectively and reducing the threats of various risks.

\section{Discussion}

Representatives of the educational and business community expressed their position on this issue. Their views were divided into two opposing camps.

Some people think that an interesting time awaits us, when artificial intelligence will play an important role in educational activities. This phenomenon is more concerned with the routine processes in pedagogy. But, sooner or later, we will face the fact that basic training will be conducted by machines. The human factor, expert assessment is not going anywhere. But the education market will change a lot. The problem of learning is the fact that people come to the courses in a non-resource state. Tests show that $60-70 \%$ of students experience professional fatigue and lack of any interest. At some point, they simply cease to show results. In this case, robots must come a step earlier, learn how to track the emotional, physical, moral state of people. Ideally, collect performance metrics and make recommendations based on them. For example, increase the duration of sleep or go on vacation. This will prevent professional burnout, which will be beneficial to the employer. Obviously, on the horizon of a large number of years, all work will be replaced by artificial intelligence. Until 2030, teachers have nothing to fear. To date, there is nothing that can replace them. In the field of automate processes the situation is different. There are bots that can solve certain narrow problems. For example, they will easily conduct an initial student survey (Anna Verba, CEO of the Aktiv Group of Companies, Georgy Kovalev, CEO PM Express, Alexander Laryanovsky, managing partner of Skyeng, Alexander Orlov, managing partner of the Stratoplan Management School, Vladimir Koval, CEO Singularika) .

One of the areas of application of artificial intelligence is education. And it is connected with the use of bots, programs based on artificial intelligence for independent communication with students. Someone is convinced that the replacement of educational activities with robots is something from the realm of fantasy and a naive illusion. Others confidently say that the machines will completely replace the teachers soon.

\section{Conclusion}

The development of applied science is one of the most important factors that have a decisive influence on scientific and technological progress and the competitiveness of the national economy. Thus, for academic science, that has main function to conduct fundamental research and education, it is one of the main tasks at the stage of ongoing transformations. This strategically important task can be realized only through the formation of an institutional environment based on the principles of partnership of educational institutions and engineering business. for the development of innovative research and educational programs focused on employer requests to increase the level of specialized education in the application of artificial intelligence in geotechnics.

Conceptual approaches to ensuring the protection and defense of human rights and freedoms in the context of using technologies and artificial intelligence units are investigated and shown. The main threats to the observance of human rights, including the 
human rights to privacy, to the confidentiality of personal information, to oblivion in a public space, to communication with another person are considered. The main approaches to the improvement of legislation in the designated area are described.

The work was supported by Act 211 of Government of the Russian Federation, contract No 2 A03. 21 11

\section{References}

1. http://www.topnews.ru/news_id_102979.html (Last accessed: September 12, 2018)

2. https://sntat.ru/obrazovanie/sem-faktov-o-legendarnom-astrofizike-stivene-khokingenevezenie-v-lyub/ (Last accessed: September 12, 2018)

3. Draft Report with recommendations to the Commission on Civil Law Rules on Robotics (2015/2103(INL)), Committee on Legal Affairs, European Parliament, Rapporteur, Mady 22 p. (2016)

4. Opinion of the European Economic and Social Committee on «Artificial intelligence The consequences of artificial intelligence on the (digital) single market, production, consumption, employment and society» (own-initiative opinion), Official Journal of the European Union, 288(01), pp. 1-9 (2017)

5. M. Gusarova, A. Kopytova, IOP Conference Series: Earth and Environmental Science, 90(1), 012034 (2017) DOI: 10.1088/1755-1315/90/1/012034

6. Robotics and artificial intelligence: A response to the House of Commons Science and Technology Committee inquiry into robotics and artificial intelligence, The Royal Academy of Engineering, p. 3 (2016)

7. The program "Digital Economy of the Russian Federation", approved by the Order of the Government of the Russian Federation dated July 28, 2017 1632-p1, Collection of the legislation of the Russian Federation, 32, Art. 5138 (2017)

8. Decree of the Government of the Russian Federation of 23.03.2018 N 482-p (as amended on 10.20.2018) "On approval of the action plan ("road map") to improve legislation and eliminate administrative barriers in order to ensure the implementation of the National Technology Initiative in the direction of "Technet" advanced production technologies) ", collection of the legislation of the Russian Federation", 09.04.2018, 15 (Part V), article 2173

9. Decreer of the Government of the Russian Federation of 01.11.2013 N 2036-p (as amended on 10/18/2018) "On approval of the Strategy for the development of the information technology industry in the Russian Federation for 2014-2020 and for the future until 2025", Collection of the legislation of the Russian Federation, 46, Art. 5954 (2013)

10. V. V. Arkhipov, V. B. Naumov, On some issues of theoretical foundations of the development of legislation on robotics: aspects of the will and legal personality, Law, 5, p. 164 (2017)

11. A. Winkler, We the Corporations: How American Business Won Their Civil Rights (Liverlight, 2018)

12. M. Karlyuk, Ethical and legal issues of artificial intelligence

13. J. McCarthy, What is Artificial Intelligence? (2007)

14. M. Andrew, Real life and artificial intelligence. "News of artificial intelligence", (RAII, 2000) 
15. M. S. Zakharov, To the question of the development of the modern paradigm of engineering geology and engineering-geological surveys, Soil Science, 5, pp. 4-7 (SPb, Regional scientific public organization "Okhotsk Society of Soil Scientists", 2014)

16. A. Kopytova, Procedia Engineering 165, 1132 (2016) DOI: 10.1016/j.proeng.2016.11.830

17. N. Zotkina, S. Bardasov, M. Gusarova, A. Kopytova, MATEC Web of Conferences, 106, 08050 (2017) DOI: 10.1051/matecconf $/ 201710608050$

18. A.V. Kopytova, Exchange of intellectual property 3 (XIV), 31-37 (2015)V. Lezier, M. Gusarova, A. Kopytova, IOP Conference Series: Earth and Environmental Science, 90 (1), 012069 (2017) DOI: 10.1088/1755-1315/90/1/012069

19. A. Winkler, We the Corporations: How American Business Won Their Civil Rights, (Liverlight, 2018) 